\title{
RESIDÊNCIA TECNOLÓGICA PARA ENGENHEIROS
}

\author{
Gilmar Laignier de Souza ${ }^{1}$, Alexandre Queiroz Bracarense ${ }^{2}$ e Marcelo Massarani $^{3}$ \\ ${ }^{1}$ FCA Latam \\ ${ }^{2}$ Departamento de Engenharia Mecânica - UFMG \\ ${ }^{3}$ Escola Politécnica - USP
}

E-mails: gilmar.laignier@fcagroup.com, queiroz@demec.ufmg.br, massara@usp.br

\section{RESUMO}

Est trabalho descreve o Programa Residência Tecnológica para Engenheiros desenvolvido na FCA - Fiat Chrysler Automobiles, em acordo com FCO - Fundação Christiano Ottoni ligada à UFMG - Universidade Federal de Minas Gerais, para facilitar a interação entre empresa e universidade. Consiste de um programa de bolsas para alunos de pós-graduação de mestrados que desenvolvam temas relacionados a questões tecnológicas atuais na FCA. Os alunos passam parte do curso pós-graduação em atividade supervisionada de pesquisa dentro da empresa para o desenvolvimento das dissertações. Espera-se desenvolver uma forma de relacionamento entre empresas e universidades que respeitem as diferenças existentes entre estas organizações.

\section{INTRODUÇÃO}

A interação entre universidade e indústria automotiva no Brasil ainda é inicial se comparada à outros setores, como construção civil, exploração de petróleo, mineração, aeronáutica, dentre outros.

A necessidade desta interação é mais intensa nos setores mais dinâmicos onde a relação entre ciência e tecnologia mais se aproxima [1], como é o caso da indústria automotiva onde o conhecimento acumulado nas empresas gera novos obstáculos que necessitam de uma atividade científica para serem superados [2]

Dosi [3] afirma que uma política industrial eficiente deve ser capaz de estabelecer uma ponte entre ciência e tecnologia e criar condições para que ocorra um acúmulo de conhecimento gerado tanto em pesquisa básica como em pesquisa aplicada. Também deve ser capaz de criar instituições que forneçam alternativas de mediação do fluxo de conhecimento entre universidade e indústria.

O programa INOVAR AUTO incentiva o relacionamento entre universidades e montadoras e fica evidente a necessidade de vencer alguns preconceitos existentes entre as organizações para que este relacionamento funcione.

A criação destas instituições é uma tarefa complexa, já que na cooperação entre universidade e empresa, segundo Plonsky [4], é necessário estabelecer um relacionamento institucional entre organizações fundamentalmente distintas, eventualmente com finalidades e formatos 
muito diferentes. Estas instituições devem ter uma estrutura enxuta e ágil de forma a minimizar os efeitos da burocracia presente tanto nas universidades públicas brasileira como nas grandes empresas.

Este trabalho descreve a implantação de uma instituição de intermediação entre universidade e empresa composta por um mecanismo de cooperação desenvolvido por iniciativa da FCA Fiat Chrysler Automobiles, em acordo com FCO - Fundação Christiano Ottoni ligada à UFMG - Universidade Federal de Minas Gerais.

\section{O PROGRAMA RESIDÊNCIA TECNOLÓGICA PARA ENGENHEIROS}

A pressão competitiva dos mercados e a necessidade de uma constante evolução tecnológica fazem com que a FCA busque alternativas científicas ao atual modelo de desenvolvimento de seus produtos. Além disso, a multidisciplinaridade das tecnologias, somada ao sistemático avanço de suas interações, aponta para a necessidade de rever o modelo mental prevalecente, ou seja, a forma de pensar dos profissionais da FCA.

A realidade atual exige um olhar mais cuidadoso para as atividades de desenvolvimento de produtos, ou seja, ter uma visão capaz de criar perspectivas científicas sobre as tarefas ditas corriqueiras. E assim, ter oportunidade de desfrutar de um potencial oculto de $\mathrm{P} \& \mathrm{D}$, contido nestas atividades. Ao ganharem fundamentação científica, essas atividades saem do universo oculto para o universo do conhecimento estruturado e explícito, expresso em documentos, por meio de relatórios, normas, dissertações e teses.

Para isso, a meta deste projeto é aproximar pesquisadores da academia aos profissionais da Fiat Chrysler Automobiles, FCA, visando o intercâmbio de conhecimentos desmistificando o paradigma das incertezas instalado em torno de projetos entre universidades e a indústria.

Pretende-se minimizar a dicotomia existente entre a formação teórica e a prática, por meio do exercício profissional, vinculando conhecimento acadêmico e a prática. Surge daí o Programa de Residência Tecnológica para Engenheiro, consolidando com o apoio do INOVAR AUTO.

Dentre as principais perspectivas do programa destaca-se a geração de espaços para aprender, ensinar, estimulando as pessoas rumo à transformação do trabalho diário, por meio de associação de recursos, em incremento dos resultados da FCA. Formalização do conhecimento da FCA; Redução de gap de competências; criação de ambientes favoráveis à inovação gerando possibilidades de melhorar o desempenho do negócio; promover a sinergia entre escola e FCA estabelecendo a difusão de conhecimentos: científico da escola e aplicado da FCA fortalecendo a competitividade; aumentar o know-how da FCA na área de parcerias com universidades e órgãos de fomento; o desenvolvimento da pesquisa cientifica e tecnológica com os conhecimentos geridos; exposição do potencial da Engenharia Automotiva brasileira às universidades gerando novas opções de aplicação dos conhecimentos desenvolvidos nas universidades e potencializar a atratividade da FCA junto ao meio acadêmico.

\section{OBJETIVO}

O Programa de Residência Tecnológica para Engenheiros tem como objetivo a pesquisa e o estímulo à inovação através da parceria com estudantes bolsistas, nível mestrado, com 
dedicação exclusiva ao tema, para atuar junto aos profissionais de engenharia no desenvolvimento de pesquisas em temas do portfólio de projetos correntes da FCA. Sob a orientação de professores universitários com experiência em pesquisas aplicadas, os bolsistas selecionados atuarão na pesquisa e desenvolvimento (P\&D), realizando estudos científicos "básicos" para aprimoramento e geração de novos métodos, tecnologias, know-how, dentre outros. Além disto, pode-se considerar também como objetivo a formação de profissionais nas diversas áreas de conhecimento para possível contratação.

\section{MODELO CONCEITUAL DO PROGRAMA}

A sociedade Brasileira assiste a uma valorização importante do trabalho em rede. Programas como o RECOPE em 1996, por exemplo, associou várias universidades e programas de pósgraduação brasileiros e até hoje frutos são colhidos destas associações. Associar recursos e competências passa a ser fundamental para a competitividade e a sociedade brasileira precisa disto. Produtos, processos e serviços evoluem no mundo em complexidade e nota-se, cada vez mais, que para avançar no mercado torna-se necessário contar com capacitações, conhecimentos, tecnologias, recursos físicos e financeiros provenientes de diferentes áreas. Ao associar o conjunto de saber da FCA, suas tecnologias, projetos, recursos físicos e financeiros ao conhecimento das universidades e ao Programa INOVAR AUTO, forma-se um grande núcleo potencial de competitividade.

Esse procedimento potencializa principalmente a capacitação dos alunos das universidades além de permitir o desenvolvimento de métodos e processos, criando espaços de aprendizagens e ensinamentos estimulando maior competitividade. Por fim, a prática orienta a evolução das pessoas envolvidas por meio de associação de recursos.

\section{OPERACIONALIZAÇÃO}

O programa baseia-se em alguns pontos fundamentais e dentre estes destaca-se a clara definição de um elemento de vinculação com a Universidade. A atividade desenvolvida se definirá por meio da escolha do Professor Orientador de determinada Universidade, convidado pela FCA, e que tenha conhecimento e concordância com a proposta do programa e que escolherá os Engenheiros Residentes Bolsistas em nível de mestrado para cada projeto do programa. Outro ponto importante é a indicação do Supervisor Técnico e Coordenador da FCA e Coordenador FCO.

A administração do Programa será feita pela FCO cujo coordenador do programa, definido como coordenador FCO/Universidade está vinculado ao Programa de pós-graduação do Departamento de Engenharia Mecânica.

Através da Fundação serão pagas as bolsas de mestrado pelo período de dois anos, assinados anualmente e renováveis por mais um ano, além da bolsa anual para os professores orientadores e o coordenador FCO/Universidade, durante o período de vigência do Programa.

Os alunos selecionados celebrarão contrato com a Universidade respectiva, devidamente reconhecida pelo $\mathrm{MEC}$ e com $\mathrm{FCO}$,. Os alunos receberão bolsa de estudo e não terão vínculo empregatício de qualquer natureza com a FCO, a instituição de ensino ou a FCA. As atividades serão desenvolvidas no período máximo de 06 (seis) horas diárias e os alunos 
poderão ficar lotados na FCA. O aluno deverá quando de sua admissão ao projeto assinar termo de sigilo, confidencialidade e propriedade intelectual, bem como deverá atestar sua dedicação exclusiva aos estudos e que reconhece a ausência do vínculo empregatício.

Na sequência destacam-se as principais participantes e papeis no Programa de Residência Tecnológica em Engenharia.

Engenheiro Residente Bolsista: É o aluno formado em engenharia, matriculado nos cursos de mestrado, com disponibilidade de dedicação exclusiva aos estudos em tema indicado e em acordo com o Professor Orientador. No período o bolsista deve desempenhar atividades compatíveis com a sua proposta de estudo acordada com o Orientador e a FCA, cumprindo cronograma que deve constar entregas de relatórios técnicos trimestrais e relatório anual. Os candidatos selecionados passarão por um Treinamento Básico Introdutório (TBI), com objetivo de conhecer as regras internas e funcionamento da FCA, conhecer as áreas de atuação, bem como o programa Inovar Auto.

Orientador: É o Professor, vinculado a alguma das universidades elegíveis. O Orientador será convidado pela FCA a integrar ao programa, e terá conhecimento e deverá concordar com os respectivos requisitos do programa.

Cabe ao Orientador o papel de atuar como um vínculo entre o Engenheiro Residente Bolsista, a Universidade e a FCA. Dentre suas responsabilidades está o permanente acompanhamento das atividades do aluno na FCA; o estabelecimento, em comum acordo com a FCA e demais interessados, do plano de atividades; a interação junto ao Supervisor nos debates para superar as dificuldades encontradas, no processo e apoio na preparação dos relatórios trimestrais e anual. Os orientadores atuam como gerenciadores dos estudos, contribuindo para que o residente bolsista consiga levar para o ambiente da FCA uma visão científica, desenvolva espirito crítico e contribua na busca recursos científicos para complementar a base de conhecimento da FCA.

Supervisor: É o Profissional vinculado à FCA que atuará como um articulador do processo dentro do ambiente de trabalho na FCA. Exige-se dele conhecimento e compreensão dos objetivos, participação na elaboração do plano de atividades, disponibilidade para reunião de ajustes com orientadores, bolsistas e coordenadores do programa. O Supervisor tem o compromisso de suportar a execução do plano do projeto e gerar meios para o compartilhamento do uso das estruturas físicas requeridas para o andamento das atividades. $\mathrm{O}$ Supervisor será responsável por avaliar os resultados obtidos ao término de cada etapa, definir e acompanhar a evolução de objetivos para cada etapa do projeto, certificar a conformidade dos resultados obtidos dos indicadores definidos no cronograma de atividades.

Coordenador FCA: É o Profissional vinculado à FCA que tem como prerrogativa a visão estratégica dos projetos, verificando o seu alcance e conduzindo o progresso de suas atividades à obtenção dos ganhos tecnológicos e cognitivos (intangíveis). A difusão do conhecimento desenvolvido por parte dos bolsistas, professores orientadores e profissionais da FCA também é objetivo da coordenação. Além de conduzir e coordenar os projetos o Coordenador tem a função de atuar como facilitador durante as fases dos projetos, interagindo setores da FCA, fornecedores e universidades, e ainda, promover ações corretivas para adequação dos resultados parciais com o objetivo proposto, garantindo assim, a execução do planejamento das atividades. 
Coordenador FCO/UNIVERSIDADES: É o Professor vinculado a Universidade que terá como prerrogativa a visão global dos projetos. O Coordenador FCO/Universidade está vinculado ao Programa de pós-graduação do Departamento de Engenharia Mecânica da UFMG. O Coordenador FCO/Universidades acompanhará juntamente com o Coordenador FCA as atividades dos projetos, reunindo-se esporadicamente com cada Professor Orientador para acertar os prazos e os termos dos relatórios, assegurando o bom andamento do Programa. O Coordenador FCO/Universidades poderá ser Orientador.

\section{PROCESSO DE SELEÇÃO DOS BOLSISTAS}

O processo de seleção será desenvolvido pelos Professores Orientadores, previamente convidados pela FCA, contemplará a identificação de candidatos com perfil adequado ao Programa e aos temas indicados pela FCA. O bolsista deve possuir o perfil para desenvolver trabalhos de pesquisa aplicada.

Serão considerados aspectos, quais sejam: trajetória acadêmica, clara compreensão dos objetivos do programa, disponibilidade para comprometer-se com as metas, capacidade de comunicação e identificação com o tema a ser estudado.

As Universidades inicialmente elegíveis ao programa são: Universidade Federal de Minas Gerais, Centro Federal de Educação Tecnológica de Minas Gerais, Universidade Federal de Ouro Preto, Universidade de São Paulo, Universidade Federal de Uberlândia, Universidade Federal de Pernambuco

\section{MANUTENÇÃO DAS BOLSAS}

Os bolsistas serão acompanhados mensalmente pelos Orientadores e trimestralmente pelo Supervisor do respectivo projeto. Eventualmente serão feitas reuniões com os Coordenadores FCA e FCO/Universidades. Relatórios mensais deverão ser gerados em modelo a ser definido pela FCA em conjunto com a FCO para gerar a memória do projeto.

Os bolsistas deverão dedicar no primeiro ano, realizar disciplinas nos respectivos Programas de Mestrado e ao desenvolvimento de revisão bibliográfica sobre o assunto do respectivo projeto. Os bolsistas deverão obter médias superiores a 70 pontos para manter a bolsa. Ao final desta etapa os bolsistas deverão defender seu projeto a frente de uma banca (Qualificação) que será composta preferencialmente pelo orientador em conjunto com dois doutores. Caso o Supervisor do respectivo projeto não tenha doutorado, terá direito a assento na apresentação.

Durante o segundo ano, os bolsistas deverão dedicar 100\% do tempo ao respectivo projeto. Ao final o projeto será defendido a frente de uma banca, não necessária a banca da qualificação, composta preferencialmente pelo orientador em conjunto com dois doutores. Caso o Supervisor do respectivo projeto não tenha doutorado, terá direito a assento na apresentação. 
O programa teve início em 2016 com a distribuição de 30 bolsas de mestrado. As bolsas têm duração de 24 meses (dois anos). As bolsas serão renovadas por um ano, dependendo do desempenho acadêmico dos estudantes.

\section{CONCLUSÃO}

O Programa de Residência Tecnológica é uma iniciativa que busca resolver algumas dificuldades no estabelecimento de parcerias entre empresas e universidades.

Estabelece um relacionamento desburocratizado entre a empresa e as universidades e aproveita o funcionamento normal dos programas de pós-graduação existentes, criando uma interface amigável entre estas organizações de natureza e objetivo distintos.

Espera-se um ganho na empresa com o estabelecimento de uma cultura relacionada com a pesquisa tecnológica para a solução dos problemas atuais ocasionado pela presença dos alunos de mestrado e doutorado e seus orientadores.

Por outro lado, os programas de pós-graduação em engenharia envolvidos poderão trabalhar no desenvolvimento de conhecimentos com aplicação imediata em produtos e processos na indústria automotiva.

Os resultados devem ser observados e analisados, já que o programa pode servir de modelo a ser usado por outras montadoras e assim estabelecer uma cooperação mais sólida entre universidades e empresas do setor automotivo.

\section{REFERÊNCIAS}

[1] COHEN, W.; NELSON, R.; WALSH, J. Links and impacts: the influence of public R\&D on industrial research. Management Science, v. 48, n. 1, p 1-23, 2002

[2] ROSENBERG, N. Por dentro da caixa preta: tecnologia e economia. Editora Unicamp. 1982.

[3] DOSI, G.. Technological paradigms and technological trajectories: a suggested interpretation of the determinants and directions of technical change. Research Policy, v.11, n.3, pp.147-162, 2008.

[4] PLONSKY, A. G. La Cooperación Empresa-Universidad en Iberoamerica, Programa CYTED, VII-XIV, São Paulo, prefácio, 1993. 